\title{
Состояние и проблемы экономики России на рубеже XIX-XX вв.
}

Л.П. БУФЕТОВА, доктор экономических наук, Новосибирский государственный университет, Новосибирск. E-mail: ludabuf@gmail.com

Год столетия октябрьского переворота 1917 г. порождает размышления о причинах событий тех далеких лет, в частности, об экономических процессах на рубеже XIX-XX веков, в период Первой мировой войны и вскоре после нее. Рассуждения о них целесообразно строить на определенных методологических предпосылках с учетом комплекса условий, меняющихся под влиянием внешних и внутренних событий.

Ключевые слова: модернизация, состояние экономики, столыпинские реформы, военный коммунизм, командно-распределительная система

Известны два, казалось бы, взаимоисключающих утверждения: в последние десятилетия перед Первой мировой войной Российская империя развивалась самыми высокими темпами среди индустриально развитых стран, а второе - Сталин получил Россию с сохой, а передал - с атомной бомбой. На наш взгляд, оба эти утверждения характеризуют состояние экономики того времени адекватно. Попытаемся разобраться в экономических событиях на рубеже XIX-XX столетий и в период Первой мировой войны, определивших характер преобразований, названных впоследствии социалистическими. При этом целесообразно исходить из того, что сфера экономической деятельности является подсистемой жизнедеятельности общества и потому испытывает влияние других подсистем: идеологии, политики, культуры, социальных отношений и т.П., значимость которых определяется множеством факторов внешнего и внутреннего порядка. Такой подход позволяет, на наш взгляд, понять следствия той или иной последовательности исторических событий.

\section{Успехи и проблемы российской экономики к началу Первой мировой войны}

Остановимся на тех аспектах состояния экономики и ее изменениях, которые, на наш взгляд, были значимы для послеоктябрьских событий. 
Рост темпов экономического развития в Российской империи был связан с развернувшейся после 1861 г. модернизацией ${ }^{1}$. Весь период российской модернизации делится на два больших временных отрезка. Первый - 1861 г. - начало 1880-х гг., второй с начала 1880-х гг. до Первой мировой войны, в свою очередь, делится на два подпериода: до окончания Русско-японской войны и Первой русской революции и короткий подпериод до начала Первой мировой войны.

Если до 1880-х гг. темпы модернизации были скромными, то второй период, несмотря на тяжелые для экономики и общества события начала XX в., отмечен самыми высокими среди индустриально развитых стран среднегодовыми темпами прироста промышленного производства: 5,8\% (против 5,2\% в США) [1. Р. 34]. Среди причин, объясняющих эти особенности развития экономики царской России в указанные периоды, назовем наиболее важные: нехватка свободной рабочей силы, а также неразвитость рыночной инфраструктуры в стране и ограниченные источники накопления капитала, способствовавшие усилению роли государства в процессе модернизации.

Первая причина проявлялась в том, что, несмотря на формальное освобождение крестьян, многие не могли покинуть аграрный сектор из-за обремененности выкупными платежами и закрепощения со стороны общины, выполнявшей в России фискальную функцию и тормозившей формирование растущего слоя свободной рабочей силы. Общинное землепользование тормозило становление рынка труда, несмотря на рост площади общинных земель (к 1905 г. примерно половина дворянских земель была передана общинам).

При этом общины на рубеже веков в России не были однородными: одни были сильны благодаря поддержке крестьян, другие - находились в состоянии распада, были общины и в зародышевом состоянии, прежде всего, в северных регионах [2. С. 142-156]. Однако, несмотря на увеличение доли общинных земель в 1905-1906 гг., Россия пережила волну крестьянских восстаний, что заставило Первую думу согласиться на реформы П.А. Столыпина. Дело в том, что крестьяне требовали увеличения

1 Предпосылки для модернизации начали складываться до отмены крепостного права, но важное условие для этого - свободная рабочая сила-появилось после 1861 г. своих наделов за счет землевладельцев, не входящих в общину. Объяснялось это тем, что крестьяне, привыкшие к периодическому переделу земель, не могли составить себе верного представления о частной собственности. Для них не было больших различий между своими правами на землю и правами крупных землевладельцев на свои имения. То есть крестьяне требовали распространения общинных принципов землепользования на соседние имения. Понятно, почему правящий класс не сразу согласился на завершение аграрных реформ второй половины XIX в. Однако с течением времени правящий класс решил: чтобы отучить крестьян от разделов, нужно сделать их собственниками земли, которую никто не может отнять. Тогда появится стимул к защите своей собственности, и крестьяне научатся уважать собственность чужую [2. С. 142-156].

Одновременно нужно иметь в виду, что состояние основной части дворянского хозяйства не позволяло рассматривать его как драйвер капиталистического ведения аграрного хозяйства в России. При этом дворянство, несмотря на свою экономическую недееспособность, угрожавшую его существованию, продолжало влиять на реальную власть для сохранения и защиты своих интересов. Была выгодна община - она защищалась, было невыгодно переселение крестьян на свободные земли - этому всячески противились. Когда стали полезными переселение крестьян за Урал и разрушение общины - изменилась государственная политика в отношении общины.

Столыпинские аграрные реформы начала XX в. были направлены на разрушение общинного уклада в аграрном секторе и укрепление в нем самостоятельных крестьянских хозяйств, производящих возрастающий объем товарной продукции. Подчеркнем, что рост аграрного производства связывался преимущественно со становлением и укреплением самостоятельных крестьянских хозяйств, а не с повышением производительности помещичьих.

Состояние аграрного сектора в условиях догоняющей модернизации играло важную роль в модернизациях многих стран как источник свободной рабочей силы и накопления капитала в ходе аграрных реформ, например, в Германии и Японии. В России этот фактор не мог полноценно проявиться.

Другой причиной медленных темпов индустриализации и ее последующего ускорения было состояние рыночных институтов 
(банковская система, институты страхования, фондовый рынок и лежащие в основе всего этого денежные инструменты и т.д.). В России, как, впрочем, и в Японии, банковская система зарождается под патронатом государства ${ }^{2}$, поскольку собственного крупного капитала, необходимого для масштабной индустриализации, в России не было. Этим во многом был обусловлен вялый рост экономики в ходе первого этапа модернизации в России: нужны были инвестиции в создание основы инвестиционного комплекса страны, мощной металлургической базы, транспортной инфраструктуры (учитывая размеры страны), для строительства машиностроительных заводов.

Выход был найден в привлечении иностранного капитала и ускоренном формировании собственного банковского сектора. В таблице 1 показано участие иностранного капитала в создании транспортной инфраструктуры.

Таблица 1. Соотношение отечественного и иностранного капитала в железнодорожном строительстве в 1861-1914 гг.

\begin{tabular}{|l|c|c|c|c|c|}
\hline \multirow{2}{*}{ Год, период } & \multirow{2}{*}{$\begin{array}{c}\text { всего } \\
\text { капитала, } \\
\text { млн руб. }\end{array}$} & \multicolumn{4}{|c|}{ В том числе: } \\
\cline { 3 - 6 } & отечественного & \multicolumn{2}{|c|}{ иностранного } \\
\cline { 3 - 6 } & 203 & 11 & 5,4 & 192 & 94,6 \\
\hline 1861 & 2097 & 128 & 6,1 & 1969 & 93,9 \\
\hline 1881 & 2918 & 553 & 18,9 & 2365 & 81,1 \\
\hline 1893 & 3856 & 619 & 15,2 & 3237 & 84,8 \\
\hline 1900 & 4341 & 1146 & 26,4 & 3195 & 73,6 \\
\hline 1908 & 4816 & 1270 & 25,5 & 3546 & 74,5 \\
\hline 1914 & 1894 & 117 & 6,2 & 1777 & 93,8 \\
\hline $1861-1881$ & 821 & 425 & 51,8 & 396 & 48,2 \\
\hline $1881-1893$ & 938 & 66 & 8,1 & 872 & 91,9 \\
\hline $1893-1900$ & 482 & 527 & 100,0 & -42 & - \\
\hline $1900-1908$ & 475 & 124 & 26,1 & 351 & 73,9 \\
\hline $1908-1914$ & & & \multicolumn{3}{|c}{} \\
\hline
\end{tabular}

Источник: [3].

Из данных таблицы видно, что на первом этапе короткие железные дороги (Москва - Курск, Москва - Воронеж, Москва Одесса и т.п.) строились за счет иностранного частного капитала.

${ }^{2}$ При этом в пореформенный период в России создавались и функционировали банкирские дома, кредитная кооперация, ссудосберегательные кассы и т.п., создававшие кредитную поддержку российскому предпринимательству на разных «этажах» экономической жизни.
После 1881 г. его участие начинает постепенно сокращаться. За весь представленный в таблице период объем иностранного капитала в строительство железных дорог России возрос в 18,5 раза, отечественного - в 115 раз.

Следует отметить, что, начиная с 1908 г., когда завершился тяжелый период в экономике России - поражение в Русско-японской войне, и после окончания Первой русской революции возросло участие отечественного капитала в создании транспортной инфраструктуры. Российский капитал постепенно берет в свои руки сопровождение модернизации страны.

Взрывной характер развития рыночной инфраструктуры на втором этапе модернизации вызван двумя причинами. Вопервых, с заимствованием иностранного опыта, прежде всего, немецкого банковского сектора, который имел практику контроля производства целых отраслей промышленности. Фактором ускорения стало заимствование акционерной формы банковского капитала, которая способствует возрастанию роли фондового рынка в рыночном распределении капитала.

Вторая причина укрепления банковского сектора связана с ролью государства: оно вкладывалось в уставной капитал первых коммерческих банков, кроме того, чиновники Министерства финансов заседали в правлениях банков, как это было при С.Ю. Витте. Витте полагал, что в России чиновник должен непосредственно участвовать в развитии разных отраслей экономики, в отличие от Англии, где, благодаря столетиям развития капитализма, все отдано частной инициативе и ответственности, а бюрократия регулирует только частную жизнь.

Выражением патернализма и слабости банковской системы России является тот факт, что до начала XX в. Центральный банк выполнял некоторые функции коммерческих банков, как, например, привлечения депозитов населения и компаний или выдачи ссуд «нужным людям».

В итоге к началу Первой мировой войны на пути модернизации России имелись как явные успехи, так и «ухабы» в виде незавершенных столыпинских аграрных реформ. Успехи России накануне Первой мировой войны проявились в том, что, по данным Р. В. Дэвиса, ее производительность труда в наиболее развитых секторах экономики составляла $50-60 \%$ от уровня, достигнутого в Англии, и не более 20-25\% - от уровня США [1. 
Р. 133]. Однако производство валового национального продукта на душу населения в 1913 г. составляло 10\% от соответствующего показателя Франции, 7\% - Англии, 4\% - США [1].

Отставание России от передовых стран мира объяснялось прежде всего тем, что накануне войны $85 \%$ населения страны жили в деревне, занимались малопроизводительным трудом в аграрном секторе, который был важным источником средств для индустриализации, благодаря экспорту сельскохозяйственной продукции.

Теперь приведем некоторые статистические иллюстрации, характеризующие результаты развития аграрного сектора в ходе столыпинских реформ (табл. 2).

Таблица 2. Урожайность продовольственного зерна и картофеля в России в 1906-1913 гг., ц/десятин

\begin{tabular}{|l|r|r|r|r|r|r|r|r|}
\hline Культура & $\mathbf{1 9 0 6}$ & $\mathbf{1 9 0 7}$ & $\mathbf{1 9 0 8}$ & $\mathbf{1 9 0 9}$ & $\mathbf{1 9 1 0}$ & $\mathbf{1 9 1 1}$ & $\mathbf{1 9 1 2}$ & $\mathbf{1 9 1 3}$ \\
\hline Пшеница & 6,0 & 6,2 & 7,5 & 8,8 & 7,9 & 4,8 & 7,0 & 9,5 \\
\hline Рожь & 6,1 & 7,4 & 7,5 & 8,5 & 8,8 & 4,8 & 9,6 & 9,1 \\
\hline Картофель & 69,6 & 74,8 & 75,5 & 81,2 & 71,2 & 74,2 & 80,4 & 75,3 \\
\hline
\end{tabular}

Источник: [4. С. 80].

Отметим очевидную тенденцию к росту урожайности основных культур. Так, урожайность зерновых культур за семь лет возросла примерно в 1,5 раза, картофеля - на 8\%.

Однако рост числа сельскохозяйственного населения с 54 до 86 млн чел. за 45 пореформенных лет снизил размер среднего надела на мужскую душу до 3,1 десятины. Много это или мало? Для сравнения: в 1907 г. соответствующий показатель для стран с более благоприятными природно-климатическими условиями составил: в Дании - 1,03 дес./душу, в Швеции - 0,92 дес./душу, во Франции - 0,82 дес./душу, в Австрии - 0,68 дес./душу, в Германии - 0,28 дес./душу, в Японии - 0,14 дес./душу [5. С. 64].

Россия, как видно, выгодно отличалась от ведущих европейских стран и Японии, где количество десятин на душу населения было в разы меньше. Но, несмотря на это, природно-климатические условия и техника обработки пашни периодически создавали угрозу голода.

Рассмотрим также некоторые показатели животноводческого сектора, продуктами которого были не только продовольственные ресурсы и сырье для пищевой промышленности, но и органические удобрения - в то время основное условие повышения продуктивности сельскохозяйственных земель в России (табл. 3).

Таблица З. Поголовье скота в России в 1900-1910 гг., голов

\begin{tabular}{|l|c|c|c|c|c|c|}
\hline \multirow{2}{*}{ Страна } & \multicolumn{2}{|c|}{ На $\mathbf{1 0 0}$ десятин земли } & \multicolumn{3}{c|}{ На $\mathbf{1 0 0}$ чел. населения } \\
\cline { 2 - 7 } & $\mathbf{1 9 0 0}$ & $\mathbf{1 9 0 5}$ & $\mathbf{1 9 1 0}$ & $\mathbf{1 9 0 0}$ & $\mathbf{1 9 0 5}$ & $\mathbf{1 9 1 0}$ \\
\hline \multicolumn{7}{|c|}{ Крупный рогатый скот } \\
\hline Россия & 2 & 2 & 3 & 33 & 34 & 31 \\
\hline Германия & 38 & 39 & 42 & 36 & 32 & 33 \\
\hline Англия & 40 & 41 & 41 & 28 & 27 & 26 \\
\hline Франция & 30 & 29 & 30 & 37 & 37 & 37 \\
\hline \multicolumn{7}{|l|}{ Овиьи } \\
\hline Россия & 4 & 5 & 4 & 53 & 63 & 48 \\
\hline Германия & 20 & 16 & 16 & 17 & 13 & 12 \\
\hline Англия & 108 & 101 & 108 & 76 & 78 & 70 \\
\hline Франция & 41 & 36 & 35 & 52 & 45 & 44 \\
\hline \multicolumn{7}{|c|}{ Свиньи } \\
\hline Россия & 1 & 1 & 1 & 11 & 10 & 8 \\
\hline Германия & 35 & 38 & 45 & 30 & 31 & 32 \\
\hline Англия & 13 & 13 & 12 & 9 & 8 & 8 \\
\hline Франция & 14 & 15 & 14 & 17 & 18 & 18 \\
\hline
\end{tabular}

Источник: [4. С. 80].

Статистические данные свидетельствуют о значительном отставании аграрного сектора царской России по количеству всех видов поголовья скота на 100 десятин земли, однако те же показатели на 100 чел. населения уже не так разительно отличаются с учетом специализации стран на выращивании тех или иных видов поголовья. То есть животноводческие ресурсы для целей питания были вполне удовлетворительными, хотя заметна тенденция к сокращению поголовья на 100 чел. населения.

В целом можно отметить, что возник своеобразный замкнутый круг: при низкой производительности труда в сельском хозяйстве значительная часть населения должна была жить в аграрном секторе, чтобы «зарабатывать» на модернизацию страны. А недостаточный уровень индустриализации в промышленности обеспечивал низкий уровень производительности аграрного труда, что являлось следствием незавершенной модернизации отрасли, не выпускавшей сельскохозяйственные машины. 
Таким образом, задачи индустриализации - создание машиностроения для замены ручного труда машинным в основных отраслях промышленности, проведение аграрной реформы и сокращение неграмотности, которые в других странах решает капитал, в Советской России должны были быть завершены новой властью в новых условиях. Что же это были за условия?

\section{Условия завершения модернизации после Октябрьского переворота}

Анализ условий следует начать с периода Первой мировой войны, поскольку именно в этот период стали складываться характеристики экономики, которую нужно было впоследствии развивать.

Первая мировая война сорвала движение России по пути модернизации. Но влияние войны заключалось не только в этом. Во-первых, разруха экономики обеспечила более низкий старт для завершения модернизации и практически «обнулила» внутренние источники накопления капитала. А во-вторых, в период войны как реакция на экономическую разруху стали складываться новые механизмы управления, названные А. А. Богдановым в июле 1917 г. военным коммунизмом. В дальнейшем остановимся на экономической стороне развития в тот период, заложивший в определенном смысле экономическую основу действий царского и Временного правительств и правительства Советской России.

Известно, что войны, финансируемые за счет денежной эмиссии при сокращении покупательной способности населения, ведут к инфляции, которая обесценивает доходы бюджета и увеличивает его расходы. Следствием разрушения денежной системы стала последовательная борьба с рынком. Действительно, поскольку важнейший инструмент рыночных взаимодействий - деньги - перестают выполнять свои функции, то нужно сворачивать и соответствующие этому инструменту институты, заменяя их административными, которые в условиях войны работают эффективно. И губернаторы, отвечающие за поставку хлеба для нужд армии, ограничили в 1915 г. свободное перемещение хлеба между рынками губерний. Затем царское правительство вводом фиксированных (указных) цен побудило крестьян срывать продажу его государству. Результатом стало введение осенью
1916 г. продразверстки. Рост администрирования экономической жизни порождал экономический саботаж, который усилил административный нажим на экономику настолько, что встал вопрос о введении государственной монополии на распределение промышленной продукции, имеющей стратегическое значение.

Этот вопрос решало уже Временное правительство, когда административные органы от волостных до общегосударственных решали множество вопросов мобилизации и распределения ресурсов. В этот же период ставится задача разработки единого народнохозяйственного плана, которая, по словам А.Ф. Керенского, связывалась «с подчинением всех частных классовых и групповых интересов, каковы бы они ни были, кем бы они ни диктовались, интересам государства» [6. С. 40]. Все мероприятия плана подлежали экспертизе для оценки их соответствия государственной политике.

Поскольку деградация денежной системы в ходе войны продолжалась, то перед Временным правительством встал вопрос о введении трудовой повинности, ибо институт заработной платы был дискредитирован и практически разрушен, потеряв свою мотивирующую функцию.

В послеоктябрьский период последствия Первой мировой войны и развернувшаяся Гражданская война диктовали продолжение борьбы с рынком, тем более что идеи коммунизма как безденежного хозяйства «овладели массами». Поэтому государственная монополия, единый план, трудовая повинность, продразверстка стали составной частью политики советского правительства. Гражданская война требовала мобилизации ресурсов всей промышленности. Поэтому была проведена ее национализация ${ }^{3}$, что стало существенным фактором для последующей победы в Гражданской войне. Все эти мероприятия получили в литературе название «политики военного коммунизма». Напомним, что понятие «военный коммунизм» было введено до событий октября 1917 г. В июле 1917 г. А.А. Богданов писал о возникающей в ходе Первой мировой войны и Февральской революции экономической системе: «Эта система "непредусмотренная"

${ }^{3}$ Первоначальные замыслы преобразования экономики не предполагали национализации промышленности. Национализации подлежала банковская система как единый расчетно-учетный центр. Эти идеи восходили к опыту немецких банков: некоторые из них контролировали целые отрасли экономики. 
и “ублюдочная", но... родители этого ублюдка - совсем не те, которым его подкидывают. Один из родителей - капитализм, правда, не подлежит сомнению, но другой - вовсе не социализм, а весьма мрачный его прообраз, военный потребительский социализм. Разница немалая. Социализм есть, прежде всего, новый тип сотрудничества: товарищеская организация производства; военный коммунизм есть прежде всего общественная форма потребления: авторитарно-регулируемая организация массового паразитизма и истребления. Смешивать не следует» [7. С. 342].

По своей экономической природе политика военного коммунизма была методом безденежной мобилизации государством ресурсов в условиях разложения денежной системы [8].

Были ли подобные события исключительно российскими или, имея экономические основания, они все же встречались в истории? Представляется, что В. Кузовков дал ответ на этот вопрос: там, где в национальных границах разрушены денежные отношения, там при распределении ресурсов объективно воспроизводятся, взамен рыночным, административные отношения [8]. И действительно, подобные мероприятия наблюдались в период Великой французской революции: хлебная разверстка, подавление частного рынка в области хлебной торговли, организация вооруженных продотрядов за хлебом в деревню, карточная система распределения хлеба, трудовая повинность и пр.

Первоначально безденежное хозяйство рассматривалось как шаг к коммунизму. Однако экономическая катастрофа к 1920 г. заставила руководство Советской России пересмотреть отношение к деньгам и торговле 4 . Состояние экономической сферы вывело ее на первые позиции в борьбе за удержание власти: экономика «взяла верх» над политикой и идеологией с их представлениями о построении безденежного хозяйства. Нам же важно понять состояние экономики, которое стало фундаментом для строительства новых экономических отношений. Здесь имеют значение два обстоятельства: разрушенные не только денежная система, но и самый передовой уклад в экономике достались в наследство новой власти (рисунок). Капиталистический уклад является более передовым по сравнению с феодальной структурой экономики.

${ }^{4}$ В 1920 г. производство продукции составляло 13\% от уровня 1913 г. В некоторых отраслях тяжелой промышленности производство практически остановилось: производство стали, например, упало до 3,6\% от уровня 1913 г.
В 1916 г. начался обвал производства товаров группы А в промышленности, выпускающей средства производства - машины, оборудование, энергетические установки, средства транспорта и т.п., т.е. обвал в самой индустриально развитой части российской экономики, созданной капиталом в активный период модернизации и во многом определяющей темпы развития экономики.

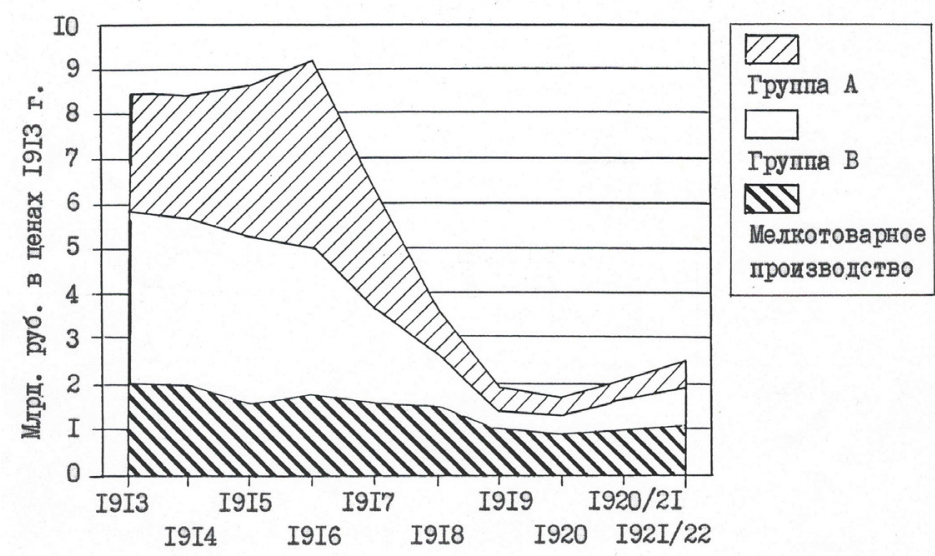

Реальный валовый выпуск промышленности в России в 1914-1921/22 гг.

Источник: [1. Р. 89].

На рисунке отчетливо видно, что обрушение промышленности началось в 1916 г. и продолжалось до 1919-1920 гг., т.е. до начала нэпа. Но самое важное обстоятельство с долгосрочными последствиями заключалось в том, что больше всего пострадал сектор производства средств производства в промышленности. Существенно сократился выпуск потребительских товаров. Мелкотоварный сектор пострадал менее всего. Это и есть иллюстрация того низкого старта, с которого начиналась новая экономика новой власти: с преобладания мелкотоварного производства и сохранения в стране патриархального уклада на фоне разрушенного индустриального. Если учесть, что накануне нэпа около 85\% населения проживало в деревне, которая еще не использовала тракторов, то становится очевидной справедливость утверждения, что Сталин принял Россию с сохой. 
Социалистическую экономику нужно было строить в условиях господства патриархального, доиндустриального уклада. И это очень важное обстоятельство, определяющее механизмы реализации целей по завершению модернизации.

Однако состояние экономики потребовало отказаться от исключительно административных способов экономического регулирования, что обеспечило заметное оживление промышленности и улучшение экономического положения крестьянства.

Политика нэпа, предоставив свободу торговле, малому и среднему бизнесу, которые не нуждались в государственной поддержке, предусматривала иную политику относительно крупных предприятий, объединенных в тресты. Предприятия разрушенного капиталистического сектора были переведены на хозяйственный расчет, но распределение созданной продукции и прибыли подлежало некоторому государственному контролю: кому и сколько продукции поставлять и в каких пропорциях распределять прибыль. Причем сектор производства средств производства был под самым пристальным контролем, в то время как предприятия по выпуску потребительской продукции максимально работали на рынок. Особое внимание крупному производству уделялось не только вследствие его значимости, но и из-за ограниченных возможностей самостоятельно в короткие сроки восстановить экономику, в отличие от мелкотоварного производства, которому лишь не нужно мешать, оно само решит свои проблемы при наличии экономической свободы.

За 1922-1928 гг. валовая продукция сельского хозяйства в сопоставимых ценах выросла вдвое, поголовье крупного рогатого скота увеличилось более чем в 1,5 раза, лошадей - на 29\% [9. С. 9]. Успехи промышленности в годы нэпа, казалось, тоже были впечатляющими: промышленное производство выросло в 3,3 раза. Однако объем потребления промышленных товаров приблизился лишь к половине от уровня 1913 г.

Важно, что начался процесс восстановления накопления капитала: в 1925 г. прибыль по отношению к уставному капиталу трестов составила от 4,6 до 7,8\%, доля собственных средств в капиталовложениях доходила до 59\%. Но за период нэпа было обновлено всего 10\% основного капитала, остальная часть только восстановлена. Следовательно, с одной стороны, можно с уверенностью говорить об определенных достижениях нэпа, с другой - недостаточной «мощи» его механизмов для достижения политико-экономических целей: восстановления экономики и формирования источников внутреннего накопления капитала для завершения модернизации.

Возникал вопрос: что делать? Ответ на него искали в дискуссиях 1920-х годов известные ученые того времени: М.И. Боголепов, В.А. Базаров, В.Г. Громан, В. Д. Кузовков, Л. Б. Кафенгауз, Н. Н. Кутлер, Н. Д. Кондратьев, Г. Л. Сокольников, Л.Н. Юровский, Т. Шанин и др.

Ответ был найден в усилении административного нажима на экономику. Он не был случайным. С одной стороны, все догоняющие модернизации XIX в. прибегали к государственному участию в ускорении модернизации. С другой - для царской России регулярная административная поддержка тех или иных экономических процессов была традицией, начиная с Петра Великого. К тому же рост монополизма в промышленности в период нэпа обусловил рост цен на промышленную продукцию крупных предприятий. Как справляться с этими экономическими явлениями? Такого опыта у руководства страны не было. Выход был найден в государственном регулировании цен на основную продукцию промышленности.

Но тогда следующий закономерный с позиции экономики шаг-регулирование распределения созданной продукции. И вот здесь политическая сфера определила дальнейшее направление развития промышленности. Представления о социалистическом производстве как единой фабрике подогревали идеи и действия по усилению администрирования экономики. Со временем огосударствление было перенесено на все сферы жизнедеятельности общества: медицину, образование, культуру, спорт и т.п., которые, вообще говоря, не являются экономическим производством. Отождествление государственной и общественной (общенародной) собственности идеологически облегчало оправдание методов администрирования.

Огосударствление определило механизмы и источники накопления ресурсов для нужд индустриализации. С помощью принуждения, сдобренного идеологическими лозунгами, источниками этого накопления стали, как известно, крестьянство, художественные ценности и ограничение потребления рабочих 
в городах путем регулирования заработной платы. Так были созданы основы мобилизационной экономики.

Административная машина всегда работает под большим политическим давлением. Удержать власть и реализовать административный нажим можно было с помощью новой идеологии, которая должна была заменить веру в бога и царя на веру в партию и коммунизм. Отсюда - особые гонения на духовенство и изъятия церковных ценностей для нужд индустриализации, поиск внутреннего врага и использование института репрессий. Новая идеология стала составной частью хозяйственного механизма новой экономической системы, которая по своей сути, на наш взгляд, не была социалистической.

\section{Заключение}

На рубеже XIX-XX веков экономика царской России пережила взлеты и падения. Взлеты были связаны с ускорением модернизации путем активного государственного вмешательства в разные секторы экономики: банковский, финансовый, инфраструктурный, военно-промышленный, а также путем бюджетной поддержки значимых частных предприятий. Реформы П.А. Столыпина сыграли свою важную роль в подготовке аграрного сектора к промышленным преобразованиям. Однако расчету на эволюционный характер аграрных преобразований не суждено было сбыться.

При всех экономических достижениях к началу XX в. российский капитал был относительно молод, зависим от бюрократии и от иностранных займов.

Первая мировая война, развернувшаяся в ее ходе Февральская революция и Октябрьский переворот существенно изменили состояние экономики. Разруха в индустриальном основании хозяйственной системы, ограниченные возможности внутреннего накопления и недоступность внешних заимствований выводили на первый план жизнеспособный сектор мелкотоварного производства, который не может быть опорой в ускорении модернизации. Это, конечно, усложняло решение задач модернизации. Задачи эти были не социалистическими, а общеэкономическими, но методы их решения - уже не капиталистическими. Потребовалось формирование мобилизационной экономики, чтобы в короткие сроки создать основу индустриального хозяйства.
Именно мобилизационный механизм управления, обусловленный отсутствием достаточного внутреннего накопления, невозможностью внешнего финансирования, поскольку советское правительство отказалось платить по царским долгам, оформил административно-распределительную систему хозяйствования. Здесь уже экономическая подсистема жизнедеятельности оказалась ведомой и несвободной.

Царское правительство и советское правительство использовали методы государственного регулирования. Но первое это делало в экономике, базирующейся на частной собственности, а второе - в экономике, построенной на основе ее огосударствления. При всей проблематичности построения социализма на индустриальной базе производства быстрое завершение модернизации в создавшихся условиях потребовало от власти особых усилий. А с учетом идеологических пристрастий эти усилия приняли форму мобилизации, репрессий, ограничения потребления населения, волюнтаризма и подавления инакомыслия.

\section{Литература}

1. The Economic Transformation of the Soviet Union. 1914-1945. Gembridge. University Press, 1994.

2. Чупров А. А. Уничтожение сельской общины в России // Вопросы экономики.- 1988.- № 10.

3. Бовыкин В. К вопросу о роли иностранного капитала // Вестник МГУ. Сер. История.- 1964.- № 1.

4. Белоусов Р. И. Две реформы//Экономист.- 1992.- № 12.

5. Зайцева Л. Земельные отношения в России в начале века и аграрная реформа Столыпина// Экономист.- 1994.- № 2.

6. Мау В. С. Реформы и догмы. 1914-1929 гг.- М.: Дело, 1993.

7. Кузовков В.Д. Основные моменты распада и восстановления денежной системы.- М.: Коммунистическая академия, 1923.

8. Богданов А. А. Вопросы социализма.- М.: Политиздат, 1990.

9. Лацис О. Выйти из квадрата.- М.: Политиздат, 1989. 